\title{
ПРЕДВАРИТЕЛЬНАЯ ГЕОМЕХАНИЧЕСКАЯ ОЦЕНКА СОСТОЯНИЯ ВОДОЗАЩИТНОЙ ТОЛЩИ НА УЧАСТКЕ РАЗВИТИЯ УСКОРЕННЫХ ОСЕДАНИЙ ЗЕМНОЙ ПОВЕРХНОСТИ
}

\author{
И.С. Ломакин \\ Горный институт УрО РАН, г. Пермь
}

\begin{abstract}
Аннотация: Анализ изменения напряженно-деформированного состояния водозащитной толщи при реализации параметров системы разработки на Верхнекамском месторождении калийных солей играет важную роль для обеспечения безопасного ведения горных работ. Целью представленной работы являлась предварительная геомеханическая оценка текущего состояния водоупорных пластов на участке развития ускоренных оседаний земной поверхности. Расчеты базировались на математическом моделировании изменения напряженно-деформированного состояния горных пород. Численная реализация осуществлялась в упругопластической постановке для условий плоского деформированного состояния методом конечных элементов. Результаты геомеханического моделирования позволили оценить достаточность предлагаемых дополнительных мер охраны.
\end{abstract}

Ключевые слова: водозащитная толща, напряженно-деформированное состояние, нарушенность горных пород, техногенная трещиноватость, метод конечных элементов.

Одной из задач безопасного ведения горных работ на рудниках Верхнекамского месторождения калийных солей (ВКМКС) является сохранность сплошности водозащитной толщи (В3Т), отделяющей продуктивные пласты от водоносных горизонтов.

В 2018 году на одном из участков отработанной площади ВКМКС было зафиксировано развитие ускоренных оседаний земной поверхности. Целью геомеханических исследований являлась оценка достаточности предложенных мер охраны ВЗТ в данной области шахтного поля, а также изменения напряженно-деформированного состояния налегающей толщи. В данной работе представлены результаты расчетов, полученные вдоль геомеханического профиля широтного простирания, пролегающего через область ускоренных оседаний земной поверхности. Принципиальная схема расчета показана на рис. 1.

Для анализа деформирования подработанного массива во времени использовался реологический подход, основанный на математическом описании прогнозных графиков нарастания оседаний земной поверхности [1].

В рамках линейной теории наследственной вязкоупругости принималось, что вертикальные смещения дневной поверхности изменяются во времени согласно соотношению:

$$
v(t)=v_{0}\left(1+\int_{0}^{t} K(\tau) d \tau\right)=v_{0}[1+\Phi(t)],
$$

где $v_{0}$ - упругие смещения, связанные с формированием выработанного пространства; $K(t-\tau)$ - функция влияния напряжения $\sigma(\tau)$ на деформацию в момент времени $t, \Phi(t)-$ функция ползучести. Поскольку реальные графики нарастания оседаний определяются разностью полных и упругих смещений, то

$$
\eta(t)=v(t)-v_{0}=v_{0} \Phi(t)
$$

Функция ползучести $\Phi(t)$ определяется фактическими или прогнозными графиками нарастания оседаний земной поверхности. 


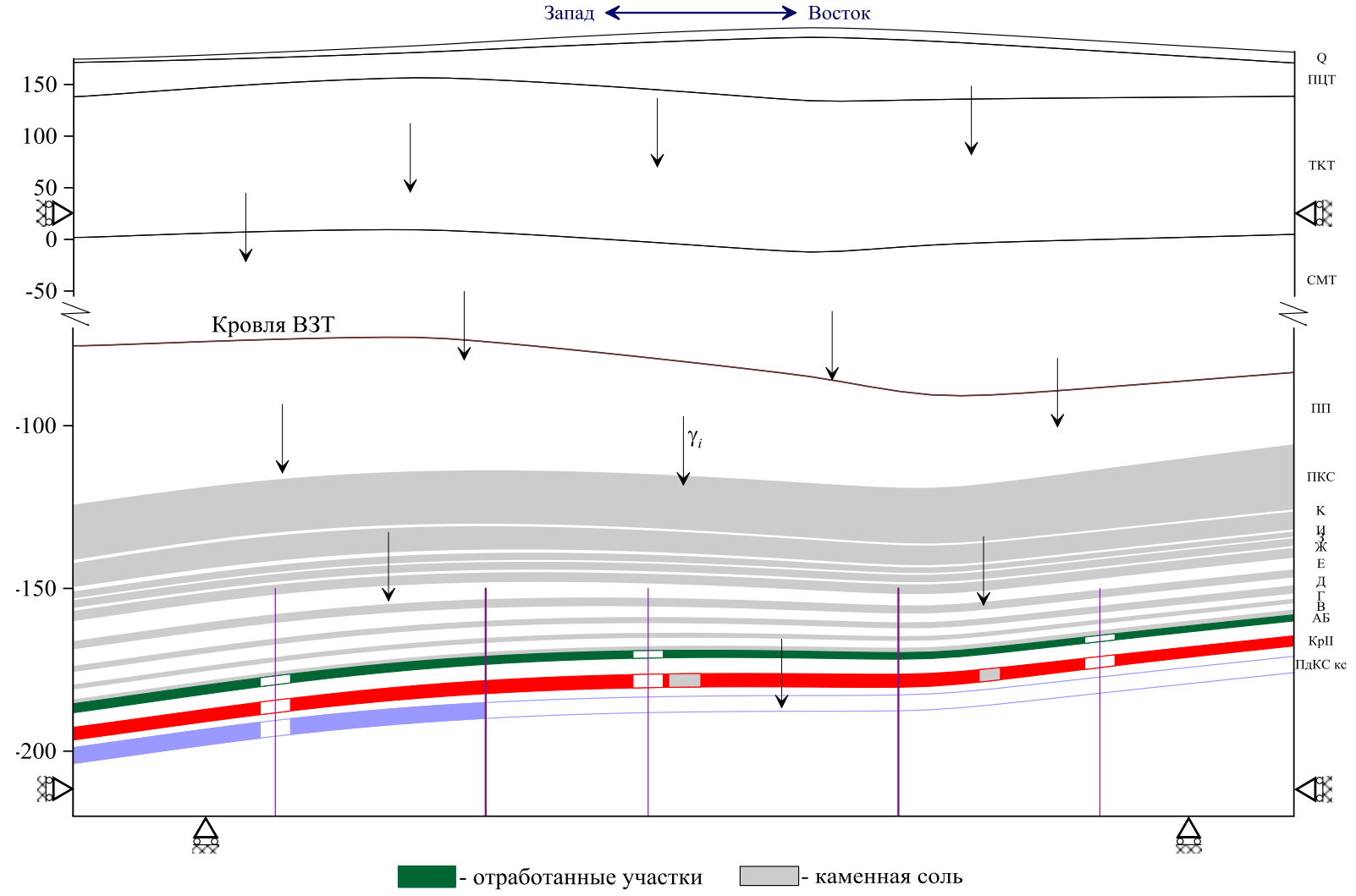

Рис. 1. Принципиальная схема расчета

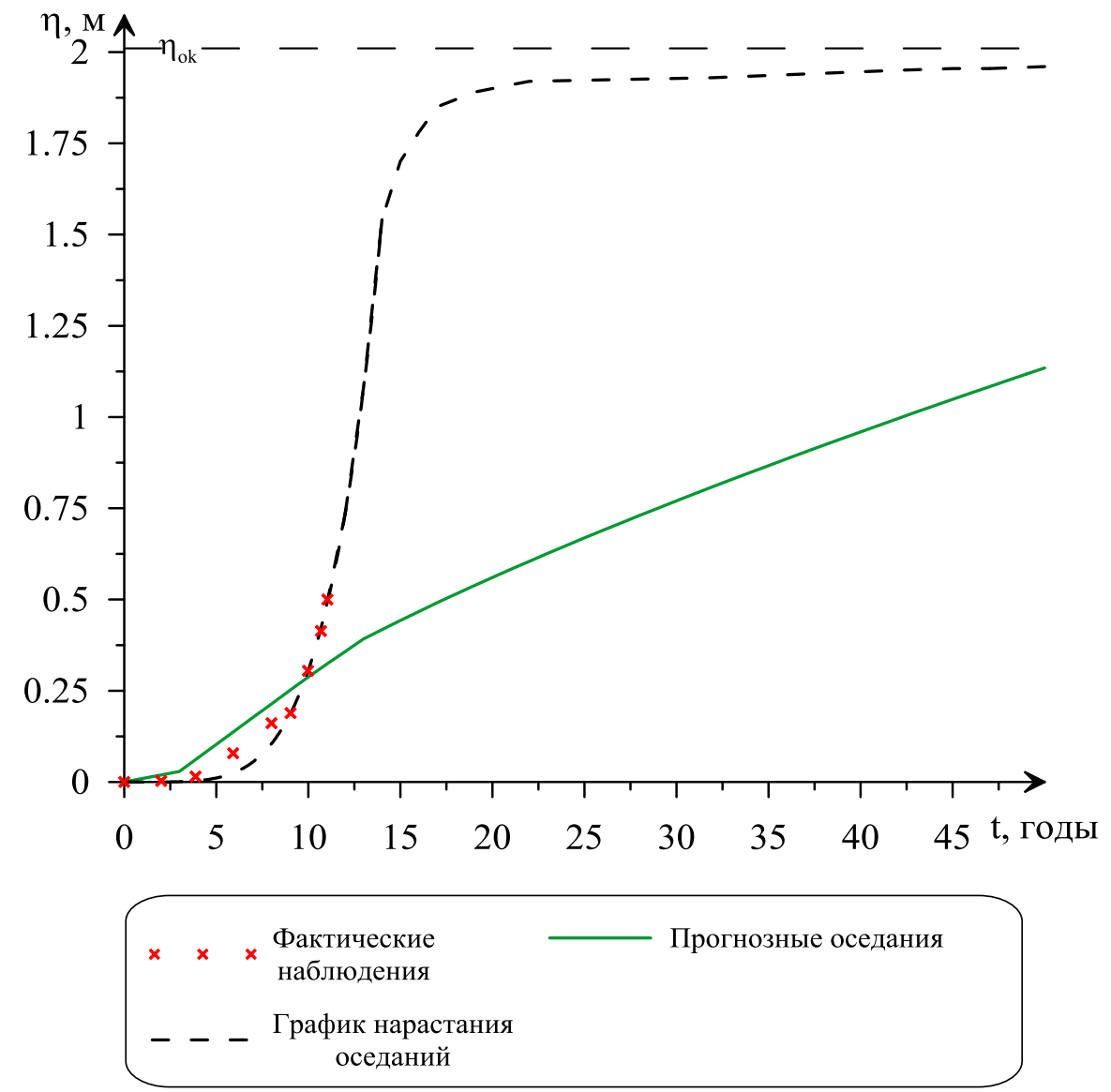

Pис. 2. Кривая нарастания оседаний земной поверхности 
На рис. 2 показана прогнозная кривая нарастания оседаний для участка развития ускоренных оседаний земной поверхности, построенная для расчетной степени нагружения междукамерных целиков согласно нормативной документации [2]. Здесь же представлены данные инструментальных наблюдений по реперу с наибольшими значениями оседаний земной поверхности. Из представленных графиков видно, что прогнозные значения оседаний не описывают наблюдаемые величины.

При оценке ситуации, сложившейся в пределах участка исследований, принималось, что увеличение скорости оседаний земной поверхности, наблюдаемое в 2018-2019 годах, сохранится в ближайшие несколько лет. В таком случае прогноз развития оседаний не может быть определен согласно нормативной документации [2]. В связи с этим на основе экстраполяции данных инструментальных наблюдений за сдвижением земной поверхности построен график нарастания оседаний с учетом их значений на конец процесса сдвижения при выполнении планируемых закладочных работ. По данному графику определялась функция ползучести согласно соотношению: $\Phi(t)=\frac{\eta(t)}{v_{0}}$. Для остальных выемочных зон определение функции ползучести $\Phi(t)$ основывалось на построении прогнозных графиков нарастания оседаний земной поверхности согласно нормативному документу [2].

В качестве определяющего уравнения нелинейной связи напряжений и деформаций использовалась идеальная упругопластическая модель, которая является обобщением упругой и жесткопластической среды с внутренним трением. Условием нарушения сплошности ВЗТ за счет образования трещин сдвига являлось выполнение неравенства

$$
\mathrm{K}_{\mathrm{K}}=\frac{\tau_{\max }}{\tau_{\text {пр }}}=\frac{\tau_{\max }}{\sqrt{\left(\sigma_{p}+\sigma_{n}\right)\left[2 \cdot \sigma_{p}-2 \sqrt{\sigma_{p}\left(\sigma_{p}+\sigma_{\text {сж⿱ }}\right)}+\sigma_{\text {сж⿱ }}\right]}} \geq 1
$$

В области растяжения предельное напряжение ограничивалось пределом прочности на растяжение:

$$
\sigma_{1}=\sigma_{\text {pacm }}
$$

Численная реализация осуществлялась методом конечных элементов в перемещениях [3] с дискретизацией рассматриваемой области на треугольные элементы первого порядка. Решение упругопластической задачи основывалось на методе начальных напряжений [4-5]. Локализация пластических деформаций в физическом смысле трактовалась как разрушение пород ВЗТ: в области сжатия вследствие развития трещин сдвига, в области растяжения - трещин отрыва. Исходя из этих позиций, проводился анализ опасности нарушения сплошности ВЗТ под воздействием горных работ.

Расчеты показали, что в случае отсутствия дополнительных мер охраны уже к 2025 году прогнозируется формирование зоны трещиноватости в нижней части В3Т над западной границей целика вдоль выработок главных направлений (рис. 3). К 2030 году нарушение сплошности охватывает всю мощность ВЗТ. Таким образом, без применения дополнительных мер охраны устойчивость ВЗТ не обеспечивается.

В целях обеспечения безопасных условий подработки ВЗТ необходимо до 2022 года выполнить закладку очистных камер пласта Кр II со степенью заполнения не менее 0,85 . Предварительные оценки показали, что при реализации принятого сценария развития процесса сдвижения земной поверхности примерно с 2025 года закладка пласта Кр II вступит в работу и начнет оказывать сдерживающее влияние на рост оседаний. В этом случае В3Т сохраняет свою устойчивость вплоть до завершения процесса сдвижения (рис. 4). 

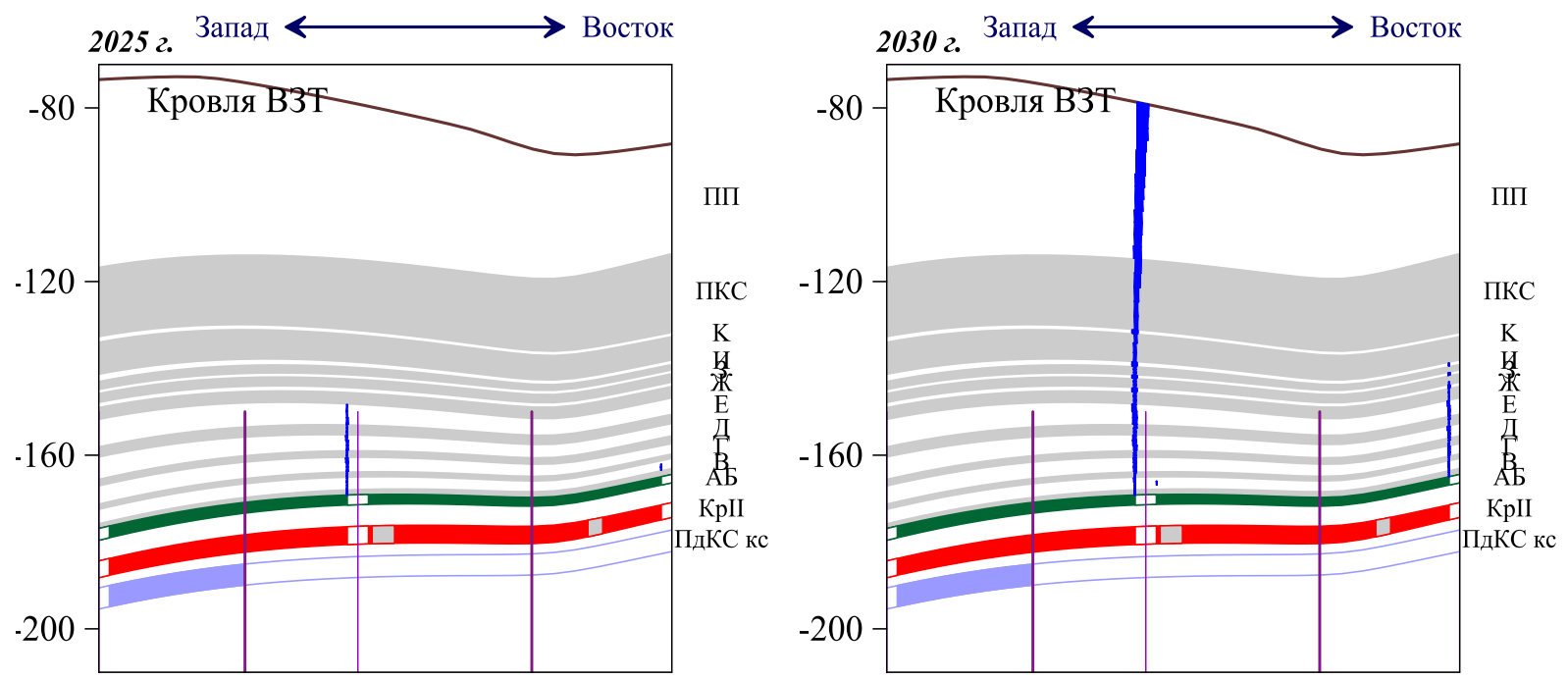

- отработанные участки $\square$ - каменная соль

- трещины сдвига

Рис. 3. Динамика развития техногенного нарушения сплошности ВЗТ без применения дополнительных мер охраны

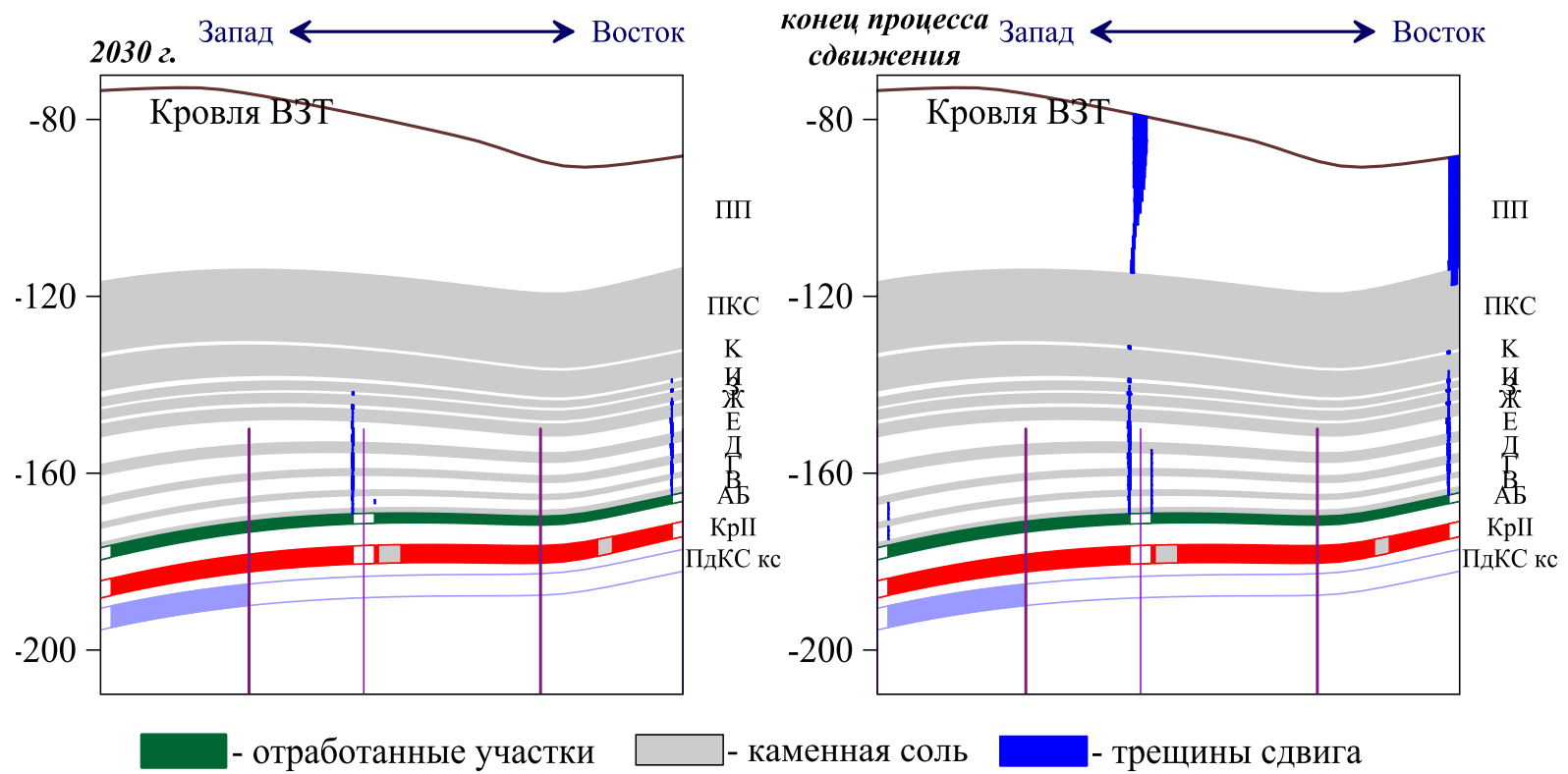

Рис. 4. Динамика развития техногенного нарушения сплошности ВЗТ при реализации дополнительных мер охраны

На основании проведенных геомеханических исследований установлено, что в случае отсутствия дополнительных мер охраны ВЗТ безопасные условия ее подработки не обеспечиваются. В сложившейся ситуации на участке развития ускоренных оседаний уже к 2025 году возможно формирование зоны трещиноватости в нижней части В3Т, а к 2030 году она способна охватить всю ее мощность. Наибольшая опасность нарушения сплошности ВЗТ связана с предохранительным целиком вдоль выработок главных направлений. В целях обеспечения безопасных условий подработки ВЗТ необходимо до 2022 года выполнить закладку очистных камер пласта Кр II на участке развития ускоренных оседаний со степенью заполнения не менее 0,85 . В этом случае В3Т сохраняет свою устойчивость вплоть до завершения процесса сдвижения. 


\title{
БИБЛИОГРАФИЧЕСКИЙ СПИСОК
}

1. Baryakh A.A., Samodelkina N.A Rheological analysis of geomechanical processes // Journal of Mining Science. - 2005. - V. 41, № 6. - P. 522-530. DOI: 10.1007/s10913-006-0015-х.

2. Указания по защите рудников от затопления и охране подрабатываемых объектов в условиях Верхнекамского месторождения калийных солей: утв. ПАО «Уралкалий», ЗАО «Верхнекамская калийная компания», ООО «ЕвроХим-Усольский Калийный комбинат». - введ. в действие 30.03.2017 в ред. 2014 г. - Пермь; Березники, 2014. - 130 с.

3. Zienkiewicz O.C. The finite element method in engineering science. - London; New York: McGraw-Hill, 1971. $-521 \mathrm{p}$.

4. Малинин Н.Н. Прикладная теория пластичности и ползучести. - М.: Машиностроение, 1975. - 400 с.

5. Фадеев А.Б. Метод конечных элементов в геомеханике. - М.: Недра, 1987. - 221 с.: ил.

УДК $539.4+519.6+622.83$

DOI:10.7242/echo.2020.4.10

\section{ЧИСЛЕННОЕ МОДЕЛИРОВАНИЕ ПОПЕРЕЧНОГО ДЕФОРМИРОВАНИЯ СОЛЯНЫХ ОБРАЗЦОВ}

\author{
А.А. Цаюков \\ Горный Институт УрО РАН, г. Пермь
}

\begin{abstract}
Аннотация: Математическое описание процесса деформирования крупномасштабных соляных образцов основывалось на упругопластической модели среды с линейным изотропным упрочнением при ассоциативном законе пластического течения. В качестве условия пластичности (трещинообразования) использовался объёмный критерий прочности горных пород, отражающий разрушение за счёт сдвига и отрыва. Численная реализация выполнялась методом конечных элементов в перемещениях. Решение систем нелинейных конечно-элементных уравнений производилось методом начальных напряжений в инкрементальной форме с постоянной матрицей жёсткости. Численное интегрирование пластических определяющих соотношений выполнялось по явной схеме алгоритма обратного отображения. По результатам расчётов откалиброванная математическая модель процесса деформирования образцов соляных пород довольно точно описывает экспериментальную кривую нагружения. Получено приемлемое соответствие экспериментальных и теоретических зависимостей поперечных деформаций от продольных. Построенная модель может использоваться для анализа устойчивости междукамерных целиков, оценки критической скорости их поперечного деформирования и остаточного срока службы.
\end{abstract}

Ключевые слова: соляные породы, механические испытания, поперечные деформации, упругопластическая модель, упрочнение, численное моделирование.

Для оперативного контроля состояния междукамерных целиков, обеспечивающих поддержание вышележащей толщи пород при подземной разработке солей, используется их поперечная деформация. Исследование развития поперечных деформаций целиков проводится в натурных и лабораторных условиях, и на их основе калибруется геомеханическая модель оценки прогнозного состояния выработок. В рамках фундаментальных исследований деформационных процессов несущих элементов камерной системы разработки был проведён лабораторный эксперимент на одноосное сжатие крупномасштабных соляных образцов кубической формы (300x300x300 мм). По его результатам построены диаграммы нагружения и зависимости поперечных перемещений реперных точек от продольных на различных расстояниях от боковых граней соляных образцов (рис. 1). В работе [1] была предпринята попытка описать кривую нагружения (рис. 1а) и показано, что использование изотропной идеальной упругопластической среды при ассоциативном законе пластического течения с критерием прочности, предложенным в 